\title{
Cyclical changes in interrenal and chromaffin cells in relation to testicular activity of olive barb, Puntius sarana (Hamilton)
}

\author{
Padmanabha Chakrabarti, Saroj Kumar Ghosh
}

Received - 23 September 2013/Accepted - 03 February 2014. Published online: 30 June 2014; Inland Fisheries Institute in Olsztyn, Poland Citation: Chakrabarti P., Ghosh S.K. 2014 - Cyclical changes in interrenal and chromaffin cells in relation to testicular activity of olive barb, Puntius sarana (Hamilton) - Arch. Pol. Fish. 22: 151-158.

\begin{abstract}
The present study focused on observations of the histological status of adrenocortical tissues and the correlated seasonal changes in testicular activities in Puntius sarana (Hamilton). Interrenal and chromaffin cells were located in the head kidney between the posterior cardinal vein and hemopoietic tissues. Various male germ cells were identified in the testis based on distinctive features, distribution, and staining properties. The cytoplasmic features and the architecture of the interrenal and chromaffin cells varied during different phases of the annual reproductive cycle. The cytoplasm mass was elevated throughout maturation and spawning phases; however, it was weak in the post-spawning and growth phases. The staining intensity changed in the cells showing various phases of secretory efficiency harmonized with the constitution of different testicular cells.
\end{abstract}

Keywords: annual cycle, histoarchitecture, adrenal, testes, Puntius sarana

\section{Introduction}

The morphology and distributional pattern of teleostean interrenal or adrenocortical and chromaffin cells are extremely diverse, and it is suggested that

\footnotetext{
P. Chakrabarti, [झ], S.K. Ghosh

Fisheries Laboratory, Department of Zoology

The University of Burdwan, Golapbag, Burdwan-713 104

West Bengal, India

Tel.: +91 342 2634798/fax. : +913422657938

e-mail: dr.pchakrabarti@yahoo.in
}

interrenal cells are homologous to the mammalian adrenal cortex, whereas chromaffin cells are homologous to mammalian medullary cells (Gazola et al. 1995). The adrenal component of teleosts is closely associated with the posterior cardinal vein and its tributaries in the cephalic head kidney. Aminergic chromaffin and interrenal steroidogenic cells can be mixed, adjacent, or completely separated and can line the endothelium of the venous blood vessels or can be located in close proximity (Gallo and Civinini 2003). The structure and pattern of the distribution of interrenal and chromaffin cells in various teleosts have been widely studied by several scientists (Yadav et al. 1970, Butler 1973, Joshi and Sathyanesan 1980, Verma and Misra 1992, Borella et al. 1999, Civinini et al. 2001, Sampour 2008); however, there is a dearth of knowledge regarding seasonal changes in the adrenal homologue in relation to teleost testicular development. Moreover, the relationships between changes in the interrenal, gonadal, and thyroidal tissue of Heteropneustes fossilis (Bloch) during different periods of the breeding cycle have been studied by Singh et al. (1974).

The aim of the present work was to examine more precisely correlative changes between the activities of the interrenal and chromaffin cells and the testis during different reproductive phases in Puntius sarana (Hamilton) (Cypriniformes: Cyprinidae) using histological analysis. To understand the 
endocrine regulation of reproduction, it is necessary to have a morpho-histological understanding of the organs involved in all the processes of the glands and gonads of mature individuals. The threatened $P$. sarana is an omnivorous, freshwater teleost that is also considered to be a palatable and economically important species. Therefore, it was an interesting subject in which to study the details of the different functional status of interrenal and chromaffin tissues in correlation with testicular development.

\section{Materials and methods}

Ten adult male specimens of $P$. sarana (14 to $16 \mathrm{~cm}$ in length and $174 \pm 3.32 \mathrm{~g}$ in weight) were procured from local freshwater bodies of Burdwan, West Bengal, India during the first week of every month from January to December 2012. After anesthetization with a $0.1 \%$ ethyl aminobenzoate solution, the fish were weighed and the total length was recorded. Data on total body weight and the weight of the testis of ten fish were collected to calculate the mean gonadosomatic index (GSI) using the following formula:

$$
G S I=\frac{\text { weight of the testes }}{\text { weight of the fish }} \times 100
$$

The head kidneys and the testes were removed immediately from the ten selected fish, cut into small pieces, and fixed in aqueous Bouin's fluid for $18 \mathrm{~h}$ for histological study. After fixation, the tissues were washed repeatedly in 70\% ethanol and dehydrated properly through ascending series of ethanol, cleared in xylene, and embedded in paraffin wax at $56-58^{\circ} \mathrm{C}$ under a thermostat vacuum paraffin-embedding bath for a period of $1 \mathrm{~h}$. After routine histological procedures, the deparaffinized sections were brought to distilled water through descending series of ethanol and stained with Delafield's hematoxylin-eosin (HE) and Mallory's triple (MT) stain. Ten to fifteen slides were prepared from each of the tissues from each fish. Sections of testes were also stained with iron alum hematoxylin (IA). All the stained slides were examined and photographed with an Olympus-Tokyo PM-6 compound microscope. The measurements of interrenal and chromaffin cells and the diameter of various spermatogenic cells were measured using an ocular micrometer. The frequency of occurrence of different spermatogenic cells were counted with a reticulomicrometer. No marked variations was observed in the tissues prepared from the ten fish specimens.

\section{Results}

Histologically, the adrenal gland of $P$. sarana consists of interrenal and chromaffin cells distributed around the main branches of the posterior cardinal vein in the anterior-most part of the pronephric kidney. The interrenal cells were eosinophilic and almost round or oval (Figs. 1 and 2). They were characterized by conspicuous, centrally-located spherical nuclei. Chromaffin cells were located close to the endothelial lining of the blood vessels and also dispersed between hemopoietic tissues and interrenal cells (Figs. 1 and 2). The cytoplasm of the interrenal cells showed basophilic coloration with Mallory's triple

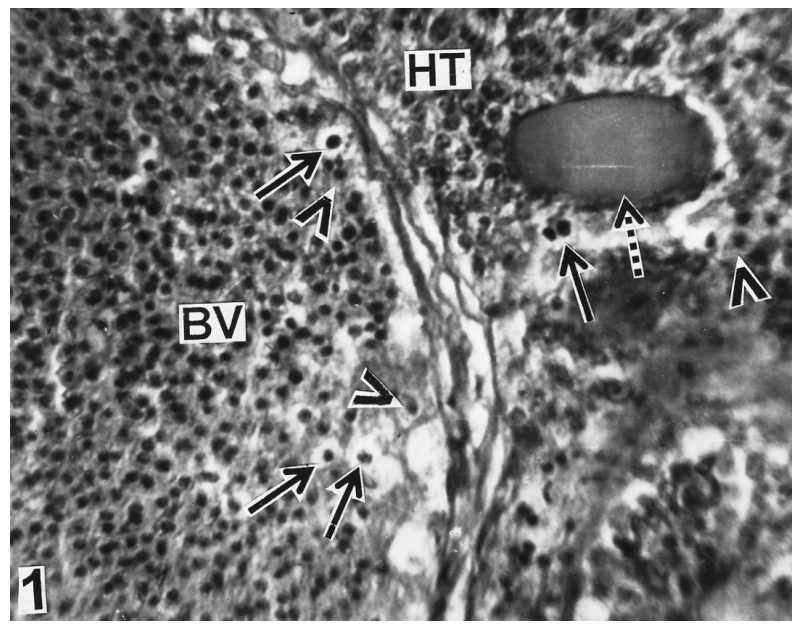

Figure 1. Photomicrographs of sections of adrenocortical tissues and testis during the growth, maturation, spawning, and post-spawning phases of $P$. sarana. (Delafield's hematoxylin-eosin - HE; Mallory's triple - MT; iron alum hematoxylin - IA). Interrenal (IR) (arrow heads) and chromaffin cells (CC) (solid arrows) within and around the blood vessels (BV) during the growth phase. Note thyroid follicle (broken arrows) between hemopoietic tissues $(\mathrm{HT})(\mathrm{HE}) \times 400$. 


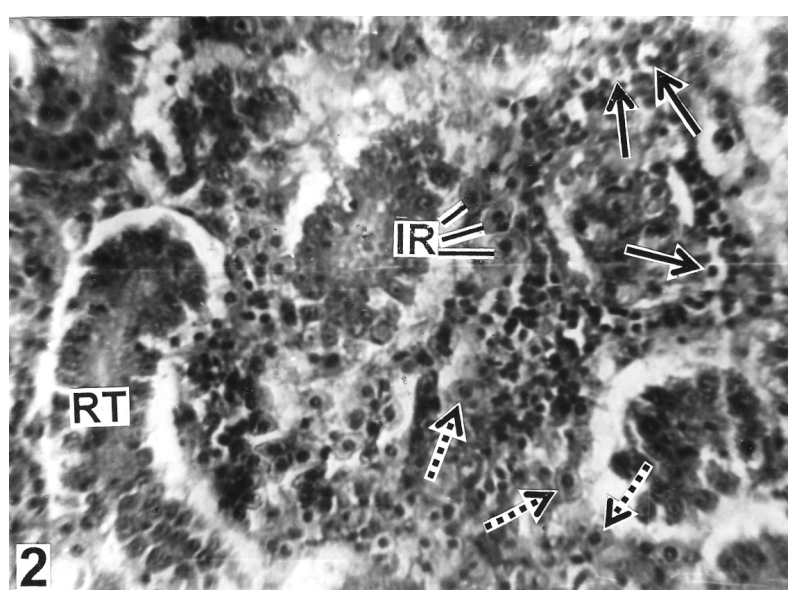

Figure 2. Oval or rounded IR with basophilic cytoplasm and prominent nuclei (broken arrows) during the growth phase. Note the presence of prominent nuclei in CC (solid arrows). RT indicates renal tubules $(\mathrm{MT}) \times 400$.

stain (Fig. 2). The chromaffin cells were eosinophobic, globular, with clean cytoplasm, and were bigger than the interrenal cells (Fig. 1).

The $P$. sarana testes were paired, elongated structures, and were solid in manifestation comprising a network of anastomosing, differently-shaped seminiferous tubules characterized by a germinal epithelium and a central lumen (Fig. 3). Interstitial cells in association with blood cells were visible in the interlobular space. Five types of germ cells, i.e., spermatogonia, primary spermatocytes, secondary spermatocytes, spermatids, spermatozoa, were noted from the periphery towards the lumen of the seminiferous tubules in various reproductive phases.

\section{Spermatogonia}

Spermatogonia were the largest of all the spermatogenic cells, and formed a nest that was attached to the inner margin of the lobule boundary wall (Fig. 3). They were almost spherical with diameters ranging from $12.83 \pm 0.05 \times 11.67 \pm 0.11 \mu \mathrm{m}$, and they had small amounts of chromophobic cytoplasm with centrally-locate nuclei $(10.89 \pm 0.14 \times$ $5.07 \pm 0.09 \mu \mathrm{m}$ ) (Fig. 3). The spermatogonia underwent several mitotic divisions and gave rise to a large number of primary spermatocytes.

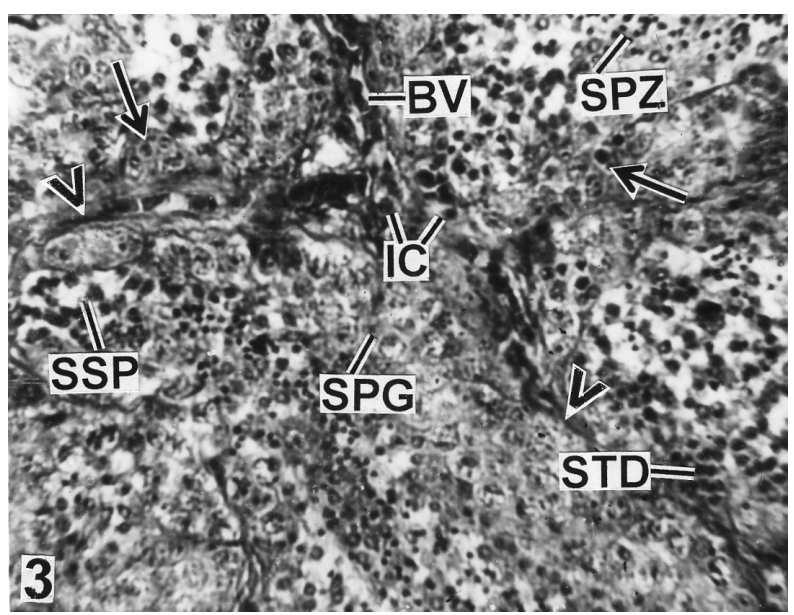

Figure 3. Different types of spermatogenic cells during the growth phase, spermatogonial cells (SPG) still present in the lobules, primary spermatocytes (PSP) (arrows), secondary spermatocytes (SSP), and spermatids (STD) are few in number. Spermatozoa (SPZ) are very few. Note prominent interstitial cells (IC) adjacent to blood vessels (BV) $(\mathrm{HE}) \times 400$.

\section{Primary spermatocytes}

The primary spermatocytes were smaller than the spermatogonial cells. They were spherical or oval with diameters ranging from $5.18 \pm 0.06 \times 4.57 \pm$ $0.13 \mu \mathrm{m}$, and they contained scanty amounts of chromophobic cytoplasm (Fig. 3). The nuclei were highly basophilic and almost round with diameters of $4.12 \pm 0.05 \mu \mathrm{m}$.

\section{Secondary spermatocytes}

The secondary spermatocytes were measured under an ocular micrometer, and they were even smaller than the primary spermatocytes. They were nearly spherical with diameters ranging from $2.61 \pm 0.13 \times$ $2.05 \pm 0.08 \mu \mathrm{m}$. The nuclei were much darker and further reduced in size (Fig. 3).

\section{Spermatids}

The spermatids were even smaller $(1.39 \pm 0.04 \times$ $1.18 \pm 0.16 \mu \mathrm{m})$. These cells stained deeply with iron alum hematoxylin (Fig. 3). They were characterized 
with extremely compact, intense basophilic elliptical nuclei. There was no visible cytoplasm.

\section{Spermatozoa}

The spermatozoa were the consequence of spermatogenesis, and they were the smallest of the spermatogenic cells with an average diameter of 0.98 $\pm 0.12 \mu \mathrm{m}$. They were more or less congruous to spermatids, but they were even smaller (Figs. 6 and 9). Since the spermatozoa tails do not stain with the hematoxylin-eosin preparation, they were not detected in the present study.

\section{Annual cyclical changes}

The activities of the interrenal and chromaffin cells undergo correlative changes during the different reproductive phases. Changes in the activities of adrenocortical tissues were studied in terms of their number, distributional patterns, and cell size along with decreases or increases of cytoplasm. Based on the histological characteristics of the testes and the gonadosomatic index (GSI) values, the $P$. sarana reproductive cycle was divided into four phases: growth (December to February), maturation (March to May), spawning (June to August), and the post-spawning and resting phases (September to November).

\section{Growth (preparatory) phase}

During the preparatory phase in the male, the interrenal cells were oval or polyhedral $(6.89 \pm 0.18$ $\mu \mathrm{m})$ with prominent, centrally-located nuclei (Figs. 1 and 2), and the cytoplasm was acidophilic. The chromaffin cells were rounded and intermingled with cortical cells and the walls of the blood vessels (Figs. 1 and 2), and they were reticulated (8.17 \pm $0.09 \mu \mathrm{m})$. The ectopic thyroid follicle was also discernible among the hemopoietic tissues and the interrenal and chromaffin cells (Fig. 1). The gonadosomatic index (GSI) values of the testes examined in the present investigation ranged from 0.25 \pm 0.11 to $0.39 \pm 0.81$. The spermatogonial cells were the principal cell type during this phase, and few primary or secondary spermatocytes or spermatids were noted. However, during the end of this phase the number of spermatids and spermatozoa was considerable (Fig. 3).

\section{Maturation (pre-spawning) phase}

During the maturation phase, the clusters of interrenal cells encircled the blood vessels and hemopoietic tissues. The cytoplasm was more acidophilic and less vacuolated (Figs. 4 and 5). The chromaffin cells were arranged in groups in between

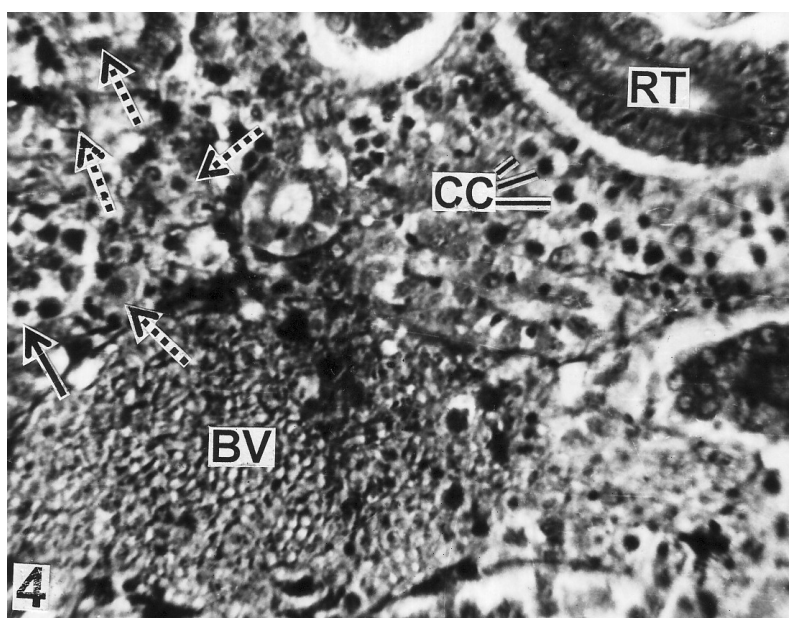

Figure 4. Orientation of IR (broken arrows) adjacent to BV and clusters of CC with non-basophilic cytoplasm during the maturation phase. RT indicates renal tubules $(\mathrm{HE}) \times 400$.

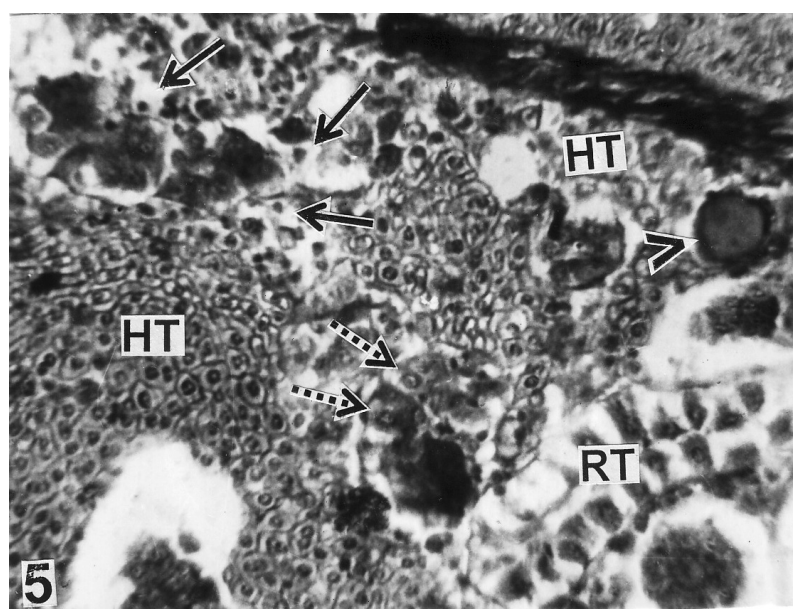

Figure 5. Gradual increment of the size of IR (broken arrows) and CC (solid arrows) during the maturation phase. Note occasional presence of thyroid follicles (arrow head) within hemopoietic tissues $(\mathrm{HT})$. RT indicates renal tubules $(\mathrm{MT}) \times 400$. 
the renal tubules and hemopoietic tissues (Figs. 4 and 5), and both the interrenal $(7.82 \pm 0.11 \mu \mathrm{m})$ and chromaffin cells $(9.01 \pm 0.05 \mu \mathrm{m})$ hypertrophied. The chromaffin cells were comparatively round or oval with large, centrally-located nuclei and non-basophilic homogenous cytoplasm (Fig. 4). In March, when testes entered the maturation phase, GSI values ranged from $0.51 \pm 0.004$ to $1.03 \pm 0.08$. The diameter of the tubules increased considerably, and all types of spermatogenic cells appeared. The number of spermatogonia decreased because they divided rapidly to produce large numbers of primary and secondary spermatocytes, spermatids, and spermatozoa (Figs. 3 and 6). At the end of this phase, the distended seminiferous lobules were full of spermatid and spermatozoa cysts. The interstitial cells in the interlobular spaces became active (Fig. 6).

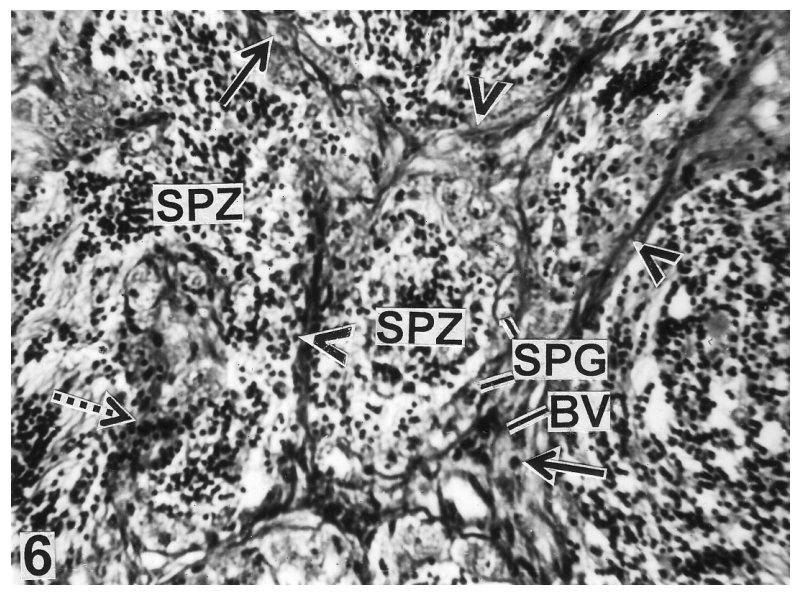

Figure 6. Spermatozoa (SPZ) fully packed in the seminiferous tubules during the maturation phase. Note cysts of spermatids (STD) (broken arrow) adjacent to SPZ. Note also interstitial cells (IC) (solid arrows) between tubules and adjacent to BV (IA) $\times 400$.

\section{Spawning phase}

In the spawning phase, the cortical and chromaffin cells changed momentously. The cortical cells were lobular or columnar with more acidophilic cytoplasm (Figs. 7 and 8). In the late spawning phase, the interrenal cells were depleted of their cytoplasmic contents and had hypertrophic nuclei (Fig. 8). The chromaffin cells were almost round with prominent nuclei, and they were stained brightly with hematoxylin-eosin (Figs. 7 and 8). Both the

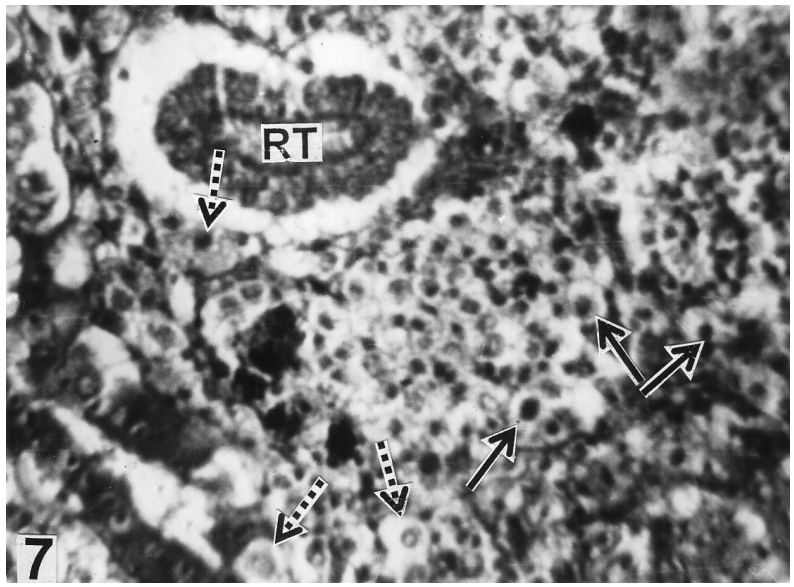

Figure 7. Hypertrophy of the IR (broken arrows) and CC (solid arrows) during the late maturation phase $(\mathrm{MT}) \times 400$.

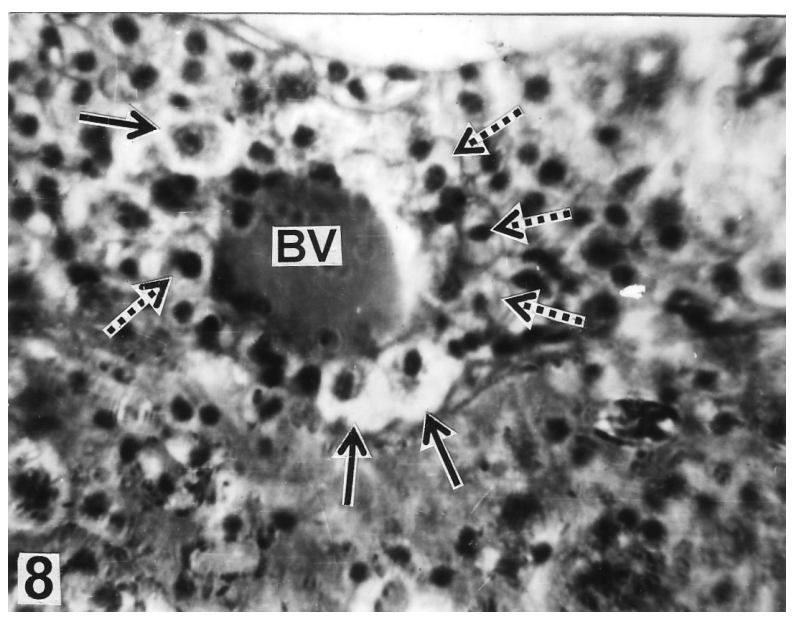

Figure 8. Maximum hypertrophy of the IR (broken arrows) and CC (solid arrows) during the spawning phase encircling blood vessels $(\mathrm{BV})(\mathrm{HE}) \times 600$.

interrenal and chromaffin cells were usually arranged in groups surrounding the blood vessels (Fig. $8)$. The GSI values recorded in the testes were $1.85 \pm$ 0.09 in June, $1.62 \pm 0.01$ in July, and $1.19 \pm 0.21$ in August. The testicular lobules attained the maximum width, and the lobule boundary wall became very thin (Fig. 9). In the late spawning phase, the lobules were packed with spermatozoa although there were many cysts containing different spermatogonial cells. The interstitial cells were frequently observed forming clusters (Fig. 9). 


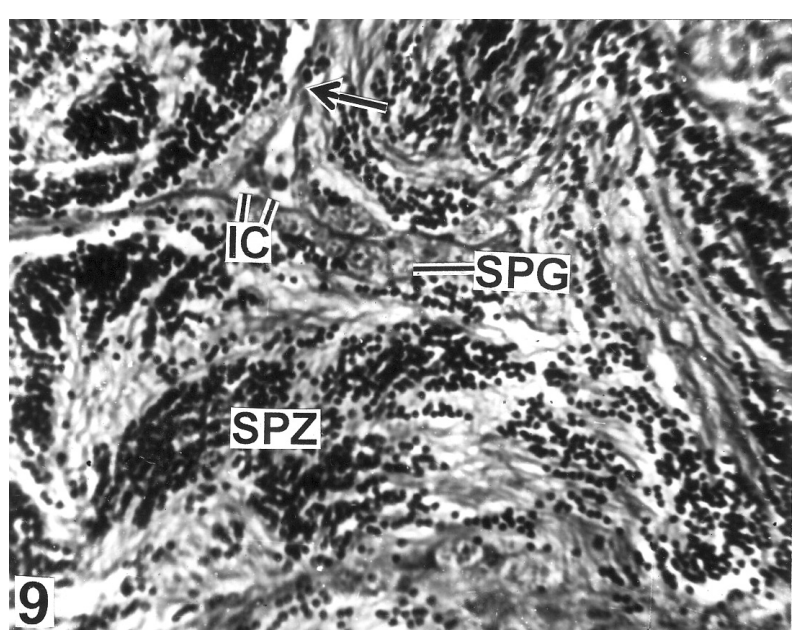

Figure 9. Packed SPZ within lobules and spermatogonial cyst (SPG) along the thickened lobule boundary wall during the late spawning phase. Note prominent IC between lobules adjacent to $\mathrm{BV}$ (arrow) $(\mathrm{MT}) \times 400$.

\section{Post-spawning (resting) phase}

During the post-spawning phase, the interrenal (6.12 $\pm 0.07 \mu \mathrm{m})$ and chromaffin cells $(7.45 \pm 0.02 \mu \mathrm{m})$ were attenuated in size and appeared vacuolated from the degradation of the cytoplasmic granules (Figs. 10 and 11). These cells were located around the blood vessels, although some interrenal cells had a considerable amount of cytoplasmic mass during this phase (Fig. 10). The cytoplasm of the chromaffin cells became vacuolated because of their degranulated, vacuolated condition (Figs. 10 and 11). The GSI value

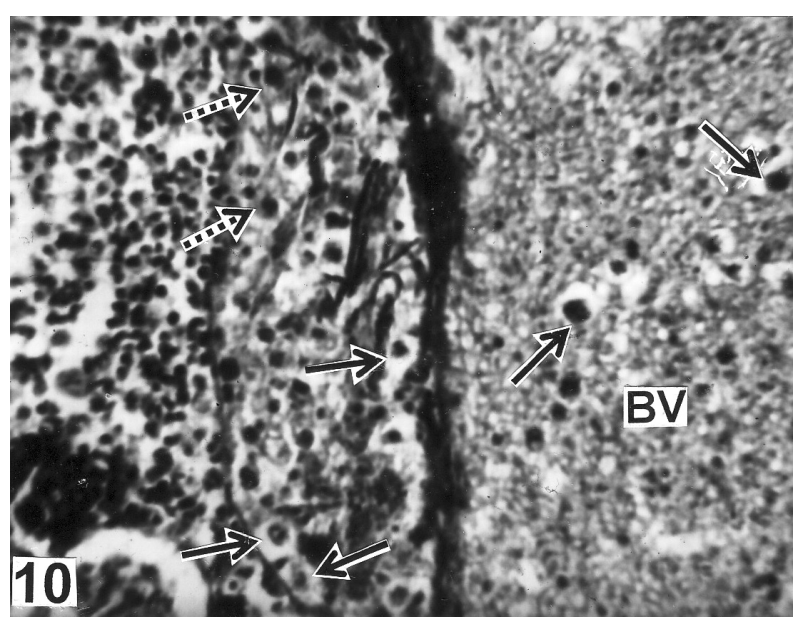

Figure 10. Reduction in size of IR (broken arrows) and CC (solid arrows) during the post-spawning phase. Note also the occurrence of some CC within $\mathrm{BV}(\mathrm{HE}) \times 400$.

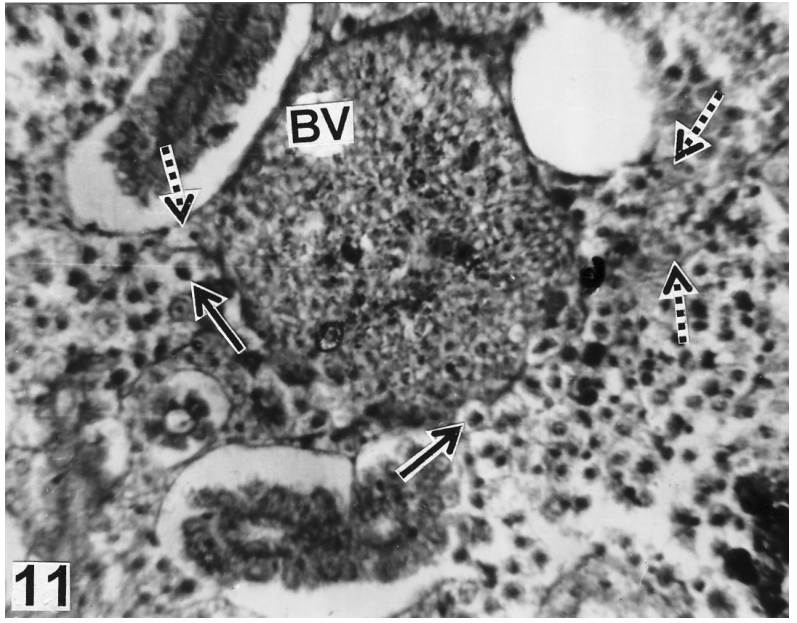

Figure 11. Reduced IR (broken arrows) and CC (solid arrows) between $\mathrm{BV}$ and renal tubules (RT) during the post-spawning phase $(\mathrm{HE}) \times 400$.

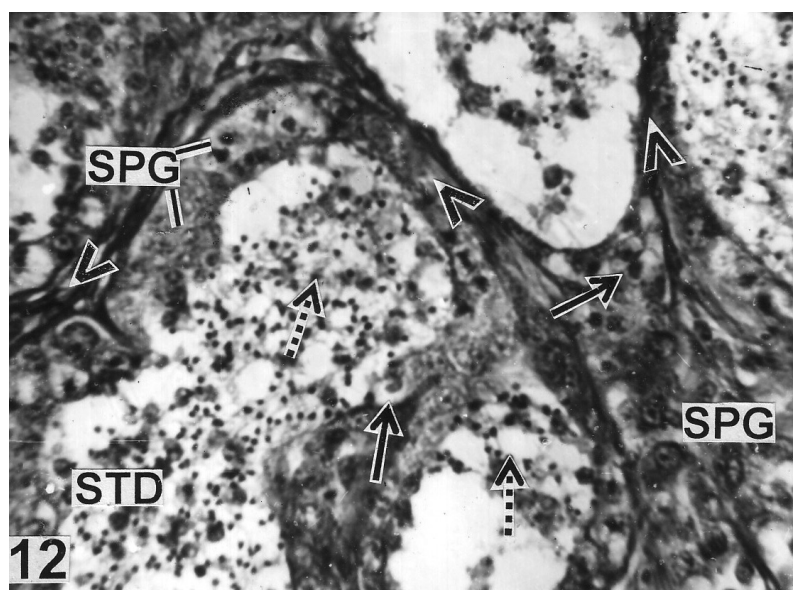

Figure 12. Residual SPZ (broken arrows) along with a few STD within lobules during the post-spawning phase. Note the thick walls of the lobules (arrow heads) and the origin of SPG along the boundary wall. Solid arrows indicate IC $(\mathrm{HE}) \times 400$.

of the testes ranged from $0.14 \pm 0.08$. The diameter of the tubules decreased and the boundary wall gradually became thicker. The residual spermatogenic cells were dispersed along with the spermatids. The lobule boundary wall was lined with spermatogonial cells (Fig. 12), and the interstitial cells were prominent between the lobules (Fig. 12).

\section{Discussion}

The interrenal cells of teleost are homologous to the mammalian adrenal cortex and are well established 
as the source of adrenocortical steroids (Chester-Jones and Philips 1986). In adult teleosts, the interrenal cells and chromaffin cells are generally exclusively in contact with the posterior cardinal veins that penetrate the anterior portion of the kidney. Similar observations were also made by Civinini et al. (2001) and Sampour (2008); however, there is diversity in the distribution and organization of interrenal and chromaffin cells, as well as in the anatomic relationships to each other and to other tissues (Nandi 1965, Banerji 1971).

In the present investigation of $P$. sarana, the interrenal and chromaffin cells were associated with the cardinal veins and their tributaries within the head kidneys. Both Thakur (1975) and Abdel-Aziz et al. (2010) consider this position to be typically teleostean. In P. sarana, the interrenal cells were comparatively larger than the chromaffin cells, and they were basophilic. The chromaffin cells contained pale cytoplasm and slightly basophilic nuclei. Although the physiological role of adrenocortical tissue during sexual maturation and spawning is not clearly understood, the hyper and hypo activity of interrenal and chromaffin tissues corresponded with the breeding and non-breeding phases of the fish studied. In the present study of $P$. sarana, the interrenal and chromaffin cells exhibited changes concomitant with testicular structures.

The accumulation of cytoplasmic contents of interrenal and chromaffin cells coincided with the transformation of various germ cells and the beginning of spermiation. The spermatogenetic activities continued until spawning. There were also a few degranulated and vacuolated interrenal cells which could have possibly released their content for spermatocyte maturation. The changes observed in the interrenal cells of $P$. sarana during spawning suggested gland hyperactivity, which could be attributed to the higher level of corticosteroid production required during spawning.

Very little research has been done on the role of adreno-cortical tissue in teleost reproduction. Ball (1960) observed interrenal cells to be active during the teleost reproductive phase. Robertson et al. (1961) clearly demonstrated gland hyperplasia during reproduction in many Salmonidae. Yadav et al. (1970) reported that epinephrine content is higher in $H$. fossilis during reproduction, but that the nor-epinephrine content does not fluctuate. According to these researchers, the rise of epinephrine content might be associated with the increased active phosphorylase levels required for metabolism during the breeding period. Nussdorfer (1986) suggested that different cytological aspects of interregnal cells can be linked to steroidogenic cells undergoing different degrees of hormonal activity. Civinini et al. (2001) reported that in the male stickleback the interregnal cells have different cytological aspects that can be linked to the steroidogenic cell cycle thus permitting the periodic renewal of organelles.

Nagahama (1994) reported that cortisol could be important to the maturation process of salmonids and cyprinid species. In P. sarana the maximum and minimum gonadal weights were recorded in July and November/December, respectively, which coincided with the maximum and minimum nuclear diameter of interrenal cells. Therefore, the activity of these cells appeared to be closely associated with gonadal activity. Gazola et al. (1995) reported that acidophilic and vacuolized cytoplasm is more pronounced in the interrenal cells of Piaractus mesopotamicus (Holmberg) during the resting stage of the reproductive cycle. According to them, this is probably related to the output of corticosteroid hormone from the cellular cytoplasm into the circulating blood. Higher rates of corticosteroid production in fishes at sexual maturity have also been reported by Robertson et al. (1961) and Donaldson and Fagerlung (1968). During the post-spawning phase, however, only a few spermatogonial cells and residual spermatozoa were noted, and the gonadosomatic index gradually decreased. Subsequent to the release of cytoplasmic contents, the cortical cells became less efficient at gonadal stimulation and were soon transformed into the chromophobic state.

The gonadosomatic index in P. sarana increased slightly during the growth period. The storage of cytoplasmic granules in the interrenal cells began at this moment, which was clearly reflected in tinctorial reactions. In Channa punctatus (Bloch), the 
interrenal cells exhibit clear seasonal changes becoming either hyperactive or inactive during the breeding and non-breeding periods of this fish species (Verma and Misra 1992).

The results obtained indicated that $P$. sarana chromaffin cells were more or less uniform in appearance except during the maturation phase when they hypertrophied. The occurrence of chromaffin cells close to the blood vessels indicated a relationship between the two structures with the former releasing their content/hormones into the blood circulation through the latter. Reid et al. (1998) suggested that in teleosts, chromaffin tissues are associated with the synthesis, storage, and secretion of the catecholamines. Sampour (2008), who interpreted the results of electron microscopic studies, observed that the presence of numerous mitochondria in different shapes in the cytoplasm of chromaffin cells probably produces energy for the activities of cells during the synthesis of catechlamine hormones. However, further studies of electron microscopy and quantitative estimations of catecholamine levels will be useful in corroborating the present findings.

Acknowledgments. Grateful acknowledgments are extended to Dr. A. Basu, Head of the Department of Zoology, University of Burdwan, for providing the necessary facilities for performing the research.

Author contributions. P.C. and S.K.G. designed and performed the research; P.C. wrote the paper.

\section{References}

Abdel-Aziz El-S.H., El-Sayed Ali T., Abdu S.B.S., Fouad H.F. 2010 - Chromaffin cells and interregnal tissue in the head kidney of the grouper, Epinephilus tauvina (Teleostei, Serranidae): a morphological (optical and ultrastructural) study - J. Appl. Ichthyol. 26: 522-527.

Ball J.N. 1960 - Reproduction in female bony fishes - Symp. Zool. Soc. London 1: 105-135.

Banerji T.R. 1971 - A comparative histological investigation on the interrenal gland of some Indian teleosts - Anat. Anz. 133: 20-32

Borella M.I., Morais C.R., Gazola R., Rossana V., Bernardino G. 1999 - Pituitary gland, gonads and interrenal gland of the immature "pacu" Piaractus mesopotamicus Holmberg, 1887 (Teleost, Characidae): morphological study - B. Téc. Cepta, Pirassununga 12: 57-70.
Butler D.G. 1973 - Structure and function of the adrenal gland of fishes - Am. Zool. 13: 839-879.

Chester-Jones I., Philips J.G. 1986 - The adrenal and interrenal gland - In: Vertebrate endocrinology (Eds) P.K.T. Pang, M.P. Schreibman, Springer Verlag, New work: 319-350.

Civinini A., Padula D., Gallo V.P. 2001 - Ultrastructure and histochemical study on the interrenal cells of the male stickleback (Gasterosteus aculeatus, Teleostea), in relation to the reproductive annual cycle - J. Anat. 199: 303-316.

Donaldson E.M., Fagerlung V.H.M. 1968 - Changes resulting from sexual maturation, in half time and volume of distribution (U) of radioactivity offer infection of $\mathrm{c}^{14}$ control $(\mathrm{F})$ into salmon - Excerpt. Med. Intern. Congr. Sen. 17: 139.

Gallo V.P., Civinini A. 2003 - Survey of the adrenal homolog in teleosts - Int. Rev. Cytol. 230: 89-187.

Gazola R., Borella M.I., Val-Sella M.V., Fava de Moraes F., Bernardino G. 1995 - Histophysiological aspects of the interrenal gland of the pacu female, Piaractus mesopotamicus (Teleostei, Cypriniformes) - B. Téc. Cepta, Pirassununga 8: 1-12.

Joshi B.N., Sathyanesan A.G. 1980 - A histochemical study on the adrenal components of the teleost Cirrhinus mrigala (Ham.) - Z. Mikrosk. Anat. Forsch. 94: 327-336.

Nagahama Y. 1994 - Endocrine regulation of gametogenesis in fish - Int. J. Dev. Biol. 38: 217-229.

Nandi J. 1965 - Interrenal morphology of some Indian cyprinid fishes - Proc. zool. Soc. Calcutta 181: 1-9.

Nussdorfer G.G. 1986 - Cytophysiology of the adrenal cortex - Int. Rev. Cytol. 98: 1-405.

Robertson O.H., Krupp M.A., Favour C.B., Hane S., Thomas S.F. 1961 - Physiological changes occurring in the blood of Pacific salmon, Oncorhynchus tshawytscha accompanying sexual maturation and spawning - Endocrinology 68: 733-746.

Reid S.G., Bernier N.J., Perry S.F. 1998 - The adrenergic stress response in fish: control of catecholamine storage and release - Comp. Biochem. Physiol. C 120: 1-27.

Sampour M. 2008 - The study of adrenal chromaffin of fish, Carassius auratus (Teleostei) - Pakistan Journal of Biological Sciences 11: 1032-1036.

Singh B.R., Thakur R.N., Yadav B.N. 1974 - The relationship between the changes in the interrenal, gonadal and thyroidal tissue of the air-breathing fish, Heteropneustes fossilis (Bloch) at different periods of the breeding cycle J. Endocrinol. 61: 309-316.

Thakur D.P. 1975 - Histochemical observations on the adrenal tissue of the teleost fish, Nandus nandus - Folia Morphol. 23: 65-70.

Verma G.P., Misra S.K. 1992 - Morphological and histochemical aspects of interrenal tissue of teleost, Channa gachua (Ham.) - Proc. Natl. Acad. Sci. India 52: 147-154.

Yadav B.N., Singh B.R., Munshi J.S.D. 1970 Histophysiology of the adrenocortical tissue of an air-breathing fish-Heteropneustes fossilis (Bloch) Mikroskopie 26: 41-49. 